Research Article

\title{
Experimental Study on Injuries to Animals Caused by a Gas Explosion in a Large Test Laneway
}

\author{
Runzhi Li $\mathbb{D}^{1}{ }^{1}$ Zhigang Zhang $\left(\mathbb{D},{ }^{1}\right.$ Rongjun Si $\mathbb{D}^{1},{ }^{1}$ Lei Wang $\mathbb{D}^{1},{ }^{1}$ Shengnan Li ${ }^{(D},{ }^{2}$ \\ Weidong Wu $\mathbb{D}^{3},{ }^{3}$ Jia Cao $\mathbb{D}^{4},{ }^{4}$ and Wenjie Ren $\mathbb{D D}^{3}$ \\ ${ }^{1}$ Fire and Explosion Prevention Research Branch, China Coal Technology and Engineering Group Chongqing Research Institute, \\ Chongqing 400037, China \\ ${ }^{2}$ School of Safety Science and Engineering, Liaoning Technical University, Huludao 125105, Liaoning, China \\ ${ }^{3}$ School of Public Health, Xinxiang Medical University, Xinxiang 453003, Henan, China \\ ${ }^{4}$ Army Medical University, Chongqing 400038, China \\ Correspondence should be addressed to Runzhi Li; runzhi_li@126.com
}

Received 21 November 2020; Revised 11 February 2021; Accepted 20 March 2021; Published 16 April 2021

Academic Editor: Qi Zhao

Copyright (c) 2021 Runzhi Li et al. This is an open access article distributed under the Creative Commons Attribution License, which permits unrestricted use, distribution, and reproduction in any medium, provided the original work is properly cited.

\begin{abstract}
Gas explosion accidents in underground coal mines caused a significant number of casualties. By using a large laneway test system, the damage to Sprague-Dawley (SD) rats at locations at different distances from the source of ignition along the direction of propagation of an explosion was investigated after $100 \mathrm{~m}^{3}$ of the gas-air mixture was ignited and exploded. In this way, the data pertaining to explosion flames and explosion pressures at different propagation distances were obtained to investigate the propagation of explosion flames and explosion pressures along the laneway. Besides, the damage to SD rats at different propagation distances was statistically analyzed. Furthermore, the damage mechanism of explosion flames, explosion pressures, and hazardous gases on humans or animals was discussed. The results indicated that explosive blast injury induced by the gas explosion was the primary reason for the death of animals and SD rats at a distance equal to or greater than $80 \mathrm{~m}$ from the point of ignition under the effects of an explosive blast even though SD rats at a distance of $240 \mathrm{~m}$ were killed. During the explosion of $100 \mathrm{~m}^{3}$ of mixed gas, the explosion flames propagated $40 \mathrm{~m}$ from the point of ignition, and the SD rats in the cage located some $40 \mathrm{~m}$ from the point of ignition were subjected to combined damage involving being burned at high temperature and suffering the effects of the explosive blast. These findings provide a theoretical basis for emergency rescue and salvage after gas explosion accidents in underground coal mines.
\end{abstract}

\section{Introduction}

China is one of the countries suffering the most serious coal mine gas explosion accidents in the world: not only are there numerous such accidents but also great harm is caused [1]. A gas explosion accident causes not only serious damage to the mine but often cause multiple casualties, with all the concomitant negative effects on society.

In recent years, the mechanism and propagation of gas explosions have been investigated experimentally or numerically [2-7]. Based on the available research, the factors influencing gas explosions in test pipelines, the propagation of explosion pressure, flames, etc., were investigated: this result is expected to provide an important theoretical basis for effectively preventing and controlling gas explosion accidents in underground coal mines. Through research, the influencing factors, explosion pressure, and flame propagation trends in a gas explosion in a test pipeline were ascertained.

Some scholars demonstrated the damage of explosive blasts on humans. For example, Bowen et al. explored human injuries and overpressure endurance under the effect of blast waves by analyzing previous clinical data and experimental results [8]. Mayorga investigated the pathology of primary explosive blast injury by analyzing previous experiments on explosive blast-induced injury and clinical 
data in the USA [9]. Owing to the data on injuries to the human bodies caused by explosions being hard to acquire, the relevant research was carried out by conducting animal experiments to reveal the damage mechanism of explosive blasts on various parts (including the brain [10-13], lung $[14]$, and eyes $[15,16]$ of animals and the influences of an explosive blast on the animal nervous system [17], food intake, and exercise performance [18]). During the propagation of a gas explosion in an underground coal mine, overpressure induced by explosive blast waves is generated [19]. In addition to this, high-temperature flames induced by a gas explosion and hazardous gases generated by incomplete combustion of gas are also important factors causing mass death and injuries to personnel in underground coal mines. As the environmental conditions in underground coal mine are difficult to simulate, research into the damage caused by gas explosions to humans or animals in practical large test laneways has not been reported.

By using a large laneway test system and taking $100 \mathrm{~m}^{3}$ of the gas-air mixture as the explosive source, the study explored the damage due to a gas explosion on SpragueDawley (SD) rats at different propagation distances based on the propagation laws governing explosion flames and pressures along the laneway. This research is expected to provide an important theoretical basis for emergency rescue and salvage after gas explosion accidents in the underground coal mines.

\section{Experimental System and Methods}

2.1. Components of the Experimental System. The experiment was conducted in a large laneway test system in Chongqing Research Institute of China Coal Technology and Engineering Group Corporation. The large laneway test system is mainly composed of a large test laneway, a comprehensive test system for explosion analysis, a gas-mixing and circulating system, and an ignition system. The system can be adopted to simulate explosion propagation experiments involving gas and coal dust at a certain scale under different conditions (Figure 1). The test laneway was $896 \mathrm{~m}$ long, and the main laneway available for the explosion experiment was about $700 \mathrm{~m}$ long. An inclined drift that was $300 \mathrm{~m}$ long at a dip angle of $24^{\circ}$ was connected to the end of the roadway. The cross-section of the laneway appeared as a semicircular arch, with an area of $7.2 \mathrm{~m}^{2}$. The test laneway is the only large test laneway in China and also the largest in the Asia-Pacific region.

The niche box was arranged in the roadway, and the niche position was fixed relative to the roadway. Pressure and flame sensors could be installed in the niche box. Niches were arranged in the laneway and pressure and flame sensors installed therein. The presence of the niches could protect connecting cables and the sensors from the explosive blast. The sensors were connected to a monitoring system in an observation room by using data lines. From the end of the laneway where the explosion started (namely, the position of the explosion-proof door), niches were installed within $40 \mathrm{~m}$ at intervals of $10 \mathrm{~m}$; beyond $40 \mathrm{~m}$ from the point of ignition, niches were arranged at intervals of $20 \mathrm{~m}$. In this experiment, a GYG1401F high-frequency dynamic pressure sensor (with a range of 0 to $0.5 \mathrm{MPa}$ ) was adopted; a GHZ5 (A) mine-safe ultraviolet flame sensor was used, which could quickly and accurately determine the presence of the flame, respectively, from $10 \mathrm{~m}$ to $140 \mathrm{~m}$. The layout of the niche box in the roadway is shown in Figure 2.

2.2. Experimental Methods. The cages for SD rats were made by welding steel members, and each cage was enclosed all around by iron wire mesh. In the test laneway whose one end was closed while the other end was open, the explosion pressure varied with the propagation distance. To ensure that the explosion pressure can cause different degrees of injuries to SD rats, six cages were installed at intervals of $40 \mathrm{~m}$ from $40 \mathrm{~m}$ away from the point of ignition at distances (for cages 1 to 6 ) to the closed end of the laneway of $40 \mathrm{~m}$, $80 \mathrm{~m}, 120 \mathrm{~m}, 160 \mathrm{~m}, 200 \mathrm{~m}$, and $240 \mathrm{~m}$, respectively. During the explosion experiment, $18 \mathrm{SD}$ rats were put into each cage. To avoid overturning of the cages, the cages were fixed to the laneway floor using setscrews (Figure 3).

During the experiment, the gas (its composition includes methane, ethane, propane, butane, hydrogen sulfide, and carbon dioxide; the extracted gas was treated by gas branch to obtain pure methane gas with a purity of $99.9 \%$ ) extracted from the local Zhongliangshan Coal Mine in Chongqing, China, was used as the explosive source and was injected into the explosion chamber in the test laneway, thus forming a gas-air mixture. The volume of the gas-air mixture was set to $100 \mathrm{~m}^{3}$ with a gas concentration of $9.0 \%$. Two fuse heads were used as ignition sources in which the energy of each forehead was $10 \mathrm{~J}$. The experimental conditions are displayed in Table 1.

This experiment was carried out three times. During the three replicate experiments, although there are some differences in the experimental data, the overall trend therein is the same. Some omissions of measured data inevitably arose: through comparative analysis, the most representative group of data was selected for analysis and research. During the experiment, $18 \mathrm{SD}$ rats were placed in each cage fixed in advance for preexperiment checks and tests on the arrangement of sensors in niches in the laneway before closing the niches. After sealing the laneway using plastic film, the hydraulic explosion-proof door was closed to form a sealed explosion chamber between the sealing film and the explosion-proof door. The volume of the sealed explosion chamber was $100 \mathrm{~m}^{3}$ according to the requirements of the experiment. By using the gas-mixing and circulating system, a certain amount of gas was injected into the explosion chamber and stirred until the gas and air were uniformly mixed. After the gas and air were uniformly mixed, the concentration was accurately measured by a CJG10 optical interference gas detector. The gas mixture was ignited to make gas explode in the laneway. Additionally, the test system was triggered to collect the explosion pressures and flame front at various measurement points along the direction of propagation of the explosive blast waves in the laneway. After completing the experiment, the air in the test laneway was exhausted via the exhaust system. After $20 \mathrm{~min}$, casualties among the SD rats in the laneway were checked. 


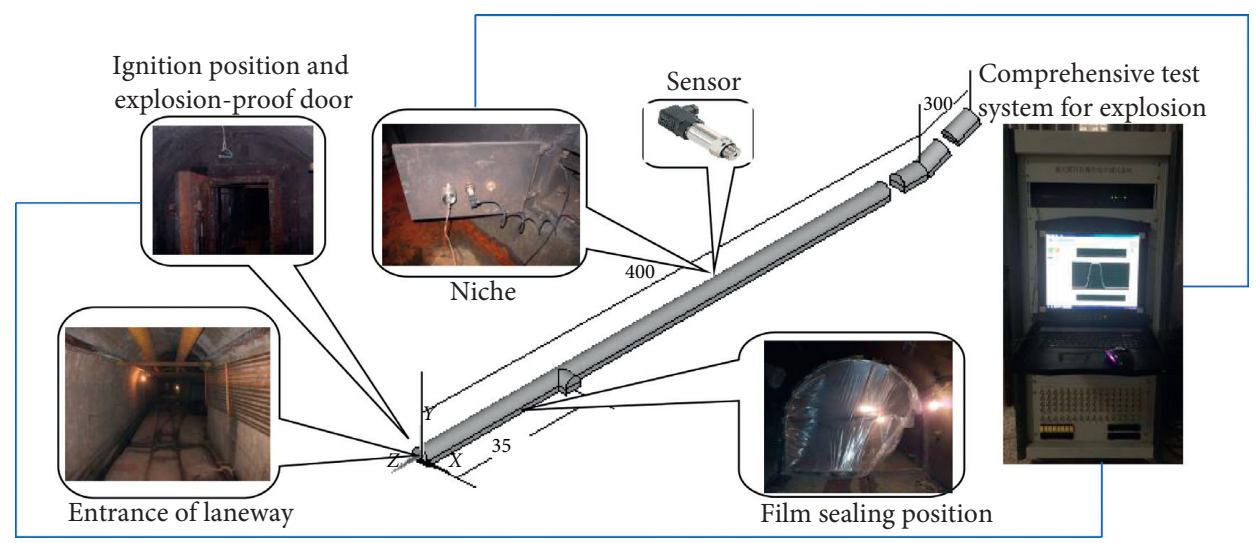

FIGURE 1: Layout of the large laneway test system.
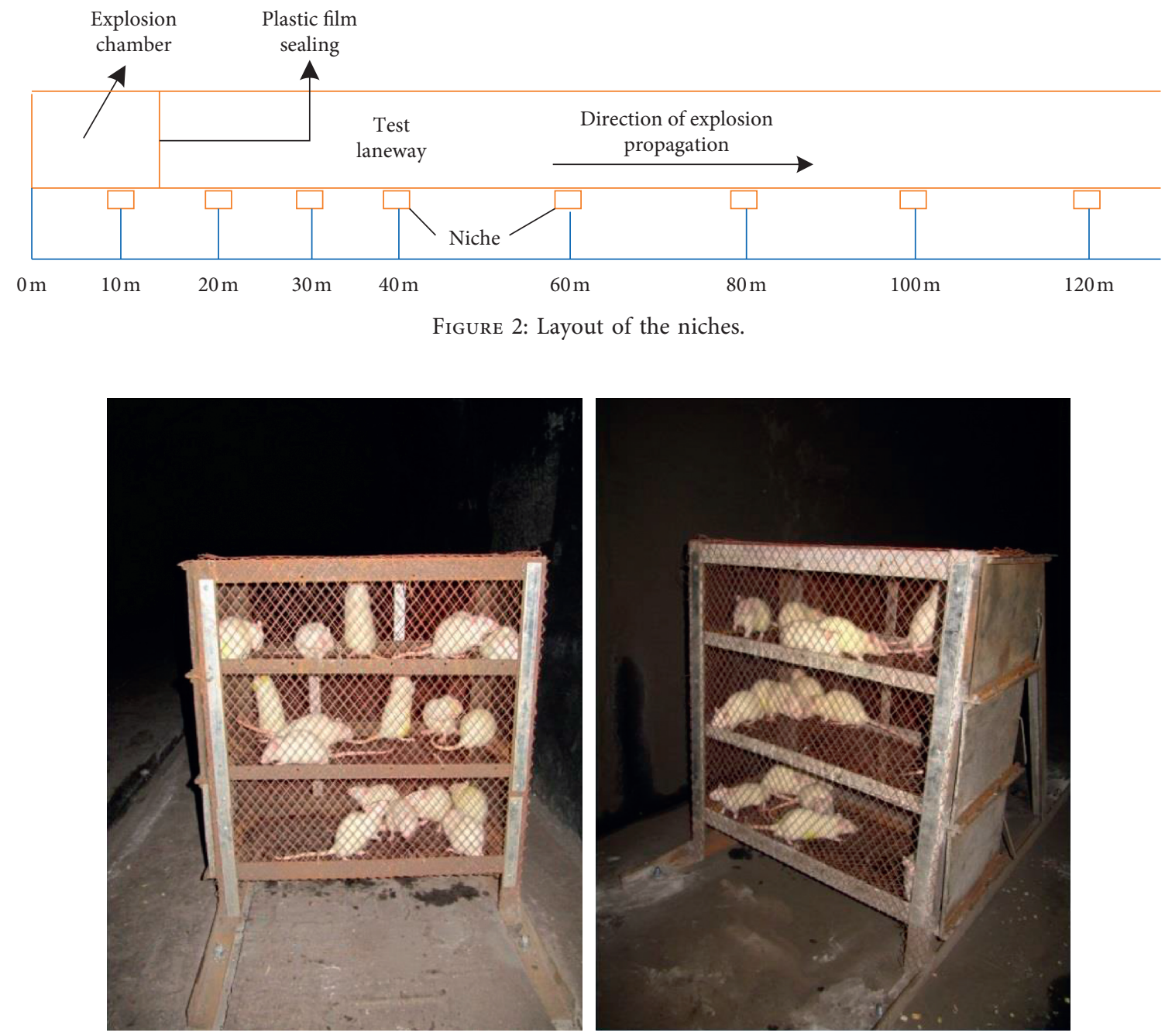

FIgUre 3: Arrangement diagrams of SD rat cages in the laneway.

TABle 1: Experimental conditions.

\begin{tabular}{lccc}
\hline Ignition energy $(\mathrm{J})$ & Volume of mixed gas $\left(\mathrm{m}^{3}\right)$ & Volume of pure gas $\left(\mathrm{m}^{3}\right)$ & Concentration of gas $(\%)$ \\
\hline 20 & 100 & 9.0 & 9.0 \\
\hline
\end{tabular}




\section{Analysis of the Propagation of a Gas Explosion}

3.1. Propagation of Explosion Flames. After conducting the explosive test, the explosion flames spread to the location at $40 \mathrm{~m}$ from the source, while no explosion flame signals were detected in the area $60 \mathrm{~m}$ and more than $60 \mathrm{~m}$ from the point of ignition. The explosion flame signals at various measuring points within the area located within $40 \mathrm{~m}$ of the point of ignition are demonstrated in Figure 4. The cross-sectional area of the test laneway was $7.2 \mathrm{~m}^{2}$. Therefore, the length of the $100 \mathrm{~m}^{3}$ of the gas-air mixture was calculated as $13.9 \mathrm{~m}$. This implied that unreacted gas flew into the area without gas during the explosion to therefore expand the range of damage of the explosion flames. If the length of the original gas-air mixture area was $L_{\text {gas }}$ and the propagation length of flames was set to $L_{\text {flame }}$, the ratio $L_{\text {flame }} / L_{\text {gas }}$ of the propagation length of flames to the length of the gas-air mixture area was 2.88 . The ratio was related to diverse factors, including the length of the gas-air mixture area, the gas concentration, and the crosssectional area of the laneway. $L_{\text {flame }} / L_{\text {gas }}$ is an important parameter. During the investigation of a gas explosion accident in a coal mine, the propagation length of flames could be judged based on burn marks of flames on structures and equipment in underground coal mines, and also the amount of gas during the gas explosion could be preliminarily estimated according to the ratio $L_{\text {flame }} / L_{\text {gas }}$.

The duration ( $T_{a}$ in Figure 4$)$ of the explosion flames can reflect the duration during which humans or animals were burned by flames during the gas explosion. The longer the duration of flames at a certain point, the more seriously humans or animals would be burned. By conducting this experiment, it can be speculated that the durations of the flames within 10 to $40 \mathrm{~m}$ from the point of ignition were $583,893,874$, and $634 \mathrm{~ms}$, respectively. The duration of the explosion flames at a location $10 \mathrm{~m}$ from the ignition position was shown to be short. It was because the explosion chamber was located in a sealed section of the laneway. After the explosion occurred, the unreacted gasair mixture broke through the sealing film and rapidly flew to the front of the laneway. As a result, the volume of gas in the original explosion chamber was rapidly decreased. At $20 \mathrm{~m}$ and $30 \mathrm{~m}$ from the point of ignition, the duration of flames was longer, which indicated that, as the explosion continued, most of the unreacted gas-air mixture in the initial stage flew into a zone 20 to $30 \mathrm{~m}$ from the point of ignition and was subjected to complete chemical reaction. As the explosion continued, gas was gradually consumed, and the explosive reaction was nearly completed when the explosion flames reached a point $40 \mathrm{~m}$ from the source. Therefore, the explosion flames there only lasted for $634 \mathrm{~ms}$, which was shorter than the duration of the flames at the locations around $20 \mathrm{~m}$ and $30 \mathrm{~m}$ from the point of ignition.

The propagation velocity of flames could be calculated by dividing the distance between two measurement points by the difference ( $T_{b}$ in Figure 4$)$ in times when the flames reached the two measurement points, as shown in the following formula:

$$
V=\frac{L_{2}-L_{1}}{T_{b}},
$$

where $L_{1}, L_{2}, T_{b}$, and $V$ represent the distances of No. 1 and No. 2 measurement points from the point of ignition, the time interval between the flames that reach the two measurement points, and the average propagation velocity of flames between the two measuring points, respectively.

The average propagation velocity of flames at different locations could be derived, as shown in Figure 5. It can be seen from the figure that the propagation velocity of flames gradually increased during the gas explosion. In the initial stage of the explosion, the propagation velocity of flames was low, merely $74.5 \mathrm{~m} / \mathrm{son}$ average in the area $10 \mathrm{~m}$ to $20 \mathrm{~m}$ from the point of ignition. As the explosion continued, the explosion flames successively propagated forwards and suffered from the compressive effect of blast waves. Therefore, the speed of the explosive reaction increased, causing the corresponding acceleration of flame propagation. The average velocity of the flames reached $339 \mathrm{~m} / \mathrm{s}$ when the flames propagated from 30 to $40 \mathrm{~m}$. As shown in Figure 4, the duration of the flames was reduced when the flames propagated to $40 \mathrm{~m}$. Moreover, no flames were detected at $60 \mathrm{~m}$ from the point of ignition, which indicated that gas had been consumed and also flames had been extinguished within 40 to $60 \mathrm{~m}$ from the point of ignition. During this process, the flame propagation velocity gradually decreased.

\subsection{Propagation of Explosion Pressures. After many tests, the} repeatability of the gas explosion propagation test in the large roadway was found to be relatively poor, and it would be affected by the weather conditions and the uniformity achieved in the mixing of the gases. The explosion pressures recorded at each measuring point would be different, but the trend therein was similar; that is, throughout the explosion and its propagation, the maximum explosion pressure at each measuring point would decay with increasing distance, but the explosion pressure was not subject to monotonic attenuation but fluctuated. Through this test, the maximum explosion pressure at each measuring point was obtained, as shown in Figure 6. By comparing and analyzing the fluctuations in the explosion pressure at each measuring point, it can be divided into three zones, namely, the pressure-relief zone after the initial breaking of the film, a zone with strengthened explosion pressure, and a zone with attenuated explosion pressure, corresponding to areas $A, B$, and $C$ in Figure 6. Among them, the pressure-relief area after the initial film broke appeared within $60 \mathrm{~m}$ of the source of the explosion; the explosion pressure enhancement area appeared between 60 and $80 \mathrm{~m}$; beyond $80 \mathrm{~m}$, the explosion pressure gradually decayed, passing out of the test roadway.

The maximum explosion pressures at various points obtained through the experiment are shown in Figure 6: the maximum explosion pressures at various measuring points showed a certain fluctuation rather than successively decreasing along the laneway during propagation. They can be divided into three zones: a pressure-relief zone after breaking the film in the initial stage, a zone with strengthened explosion 

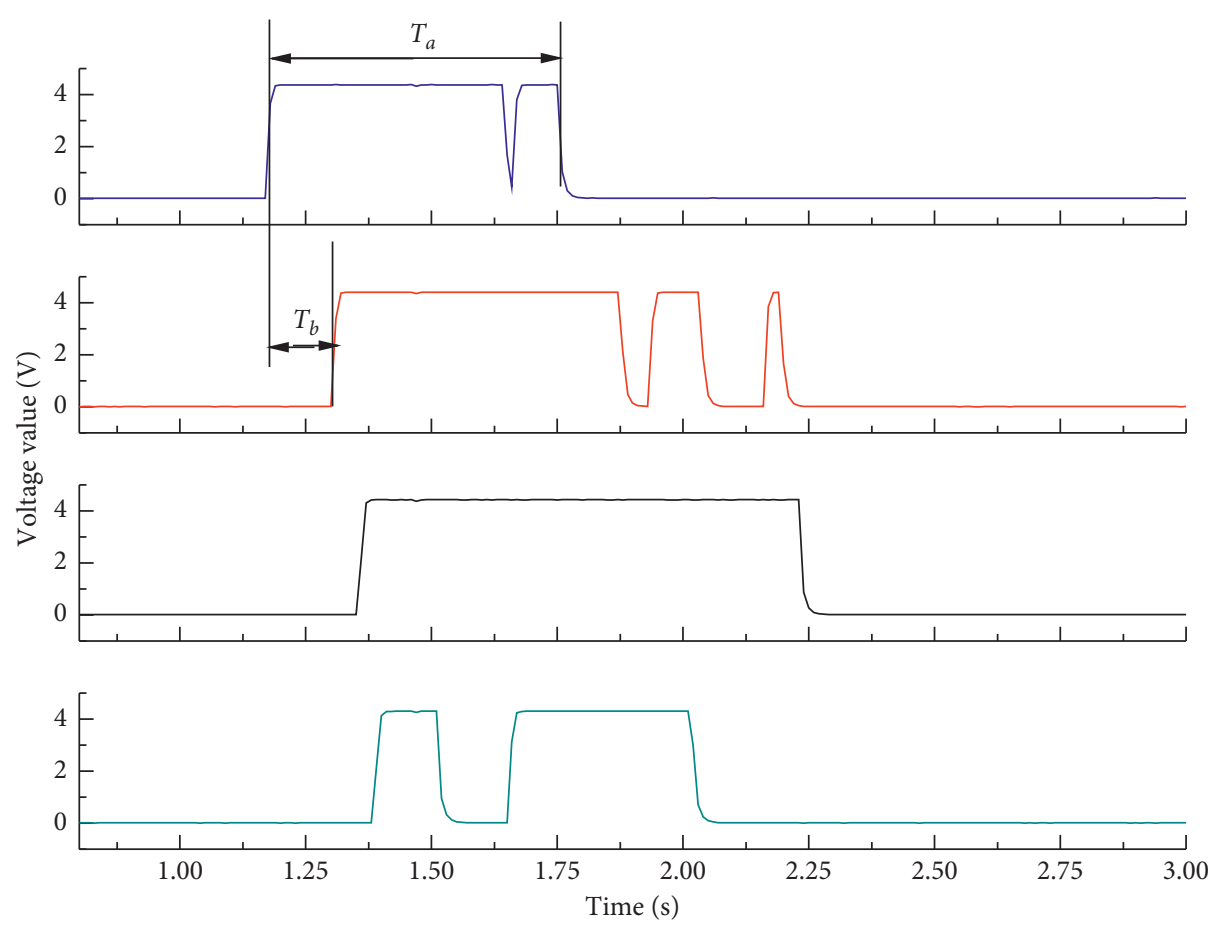

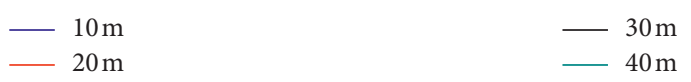

FIgURE 4: Flame signals at various measurement points.

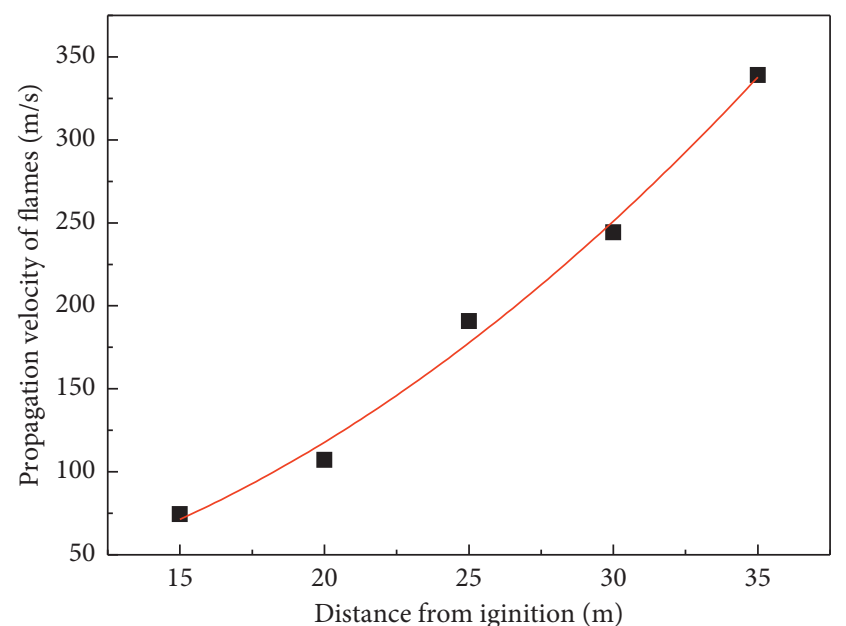

- Test value

- Fitting curve

Figure 5: Average flame propagation velocities at different locations.

pressure, and a zone with attenuated explosion pressure, which, respectively, corresponded to zones $A, B$, and $C$ in Figure 6 . Zones $A$ and $B$ were separately $60 \mathrm{~m}$ and 60 to $80 \mathrm{~m}$, from the point of ignition. After reaching a point about $80 \mathrm{~m}$ from the point of ignition, the explosion pressure gradually decreased until propagation went beyond the test laneway.

After the gas-air mixture was ignited, a spherical flame front was immediately formed to propagate towards the

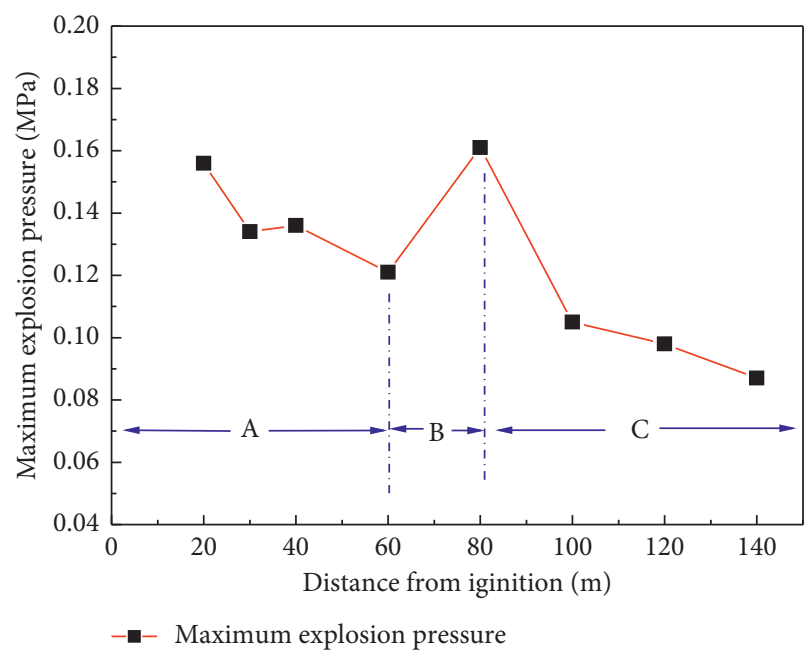

FIGURE 6: The maximum explosion pressures at various measurement points.

unburned gas. The flame front rapidly propagated to the whole cross-section of the laneway and therefore rapidly generated pressure waves in the narrow, confined space. The propagation velocity of the pressure wave was greater than that of the burning front; therefore, the pressure wave went ahead of the burning front, which was also called the precursor blast wave (or precursor pressure wave). The gas pressure behind the wave increased and the gas flew (generating a storm-force wind) to result in damage to the sealing film and further caused the release of a certain amount of 
pressure. Thus, in the initial propagation stage of this gas explosion, the peak explosion pressure decreased slightly. As the propagation distance increased, the explosion pressure rose owing to it being restricted by the narrow space in the laneway, namely, a zone with strengthened explosion pressure developed. In these experimental conditions, the volume of the gas-air mixture was $100 \mathrm{~m}^{3}$. As the gas during the explosion reaction was gradually consumed, the explosion pressure gradually declined and therefore a zone with attenuated explosion pressure developed.

During the propagation of the explosion, the change in explosion pressure from $20 \mathrm{~m}$ from the point of ignition with time is shown in Figure 7. The explosion pressure at the location rapidly increased at first and then rapidly reduced and became negative after a certain time. After the gas explosion, the air in the vicinity of the explosive source was diffused as driven by high temperature and pressure, and thus, blast waves were generated along the diffusion path, resulting in the rapid increase in the explosion pressure. However, after the explosive blast waves passed through, the gas-air mixture rapidly flew forwards and therefore formed a certain negative pressure at that location. The negative pressure caused a backflow of air after the explosion. During a gas explosion in an underground coal mine, the positive and negative pressures triggered by the explosion can cause harm to personnel and damage to equipment.

By analyzing the explosion flames, it can be seen that the duration of the flames was longest, and the explosion reaction was mostly completed, at $20 \mathrm{~m}$ from the point of ignition. Additionally, explosion pressure at the location was large, reaching $0.156 \mathrm{MPa}$ at $1,369 \mathrm{~ms}$. For convenience of analysis and calculation, the time when flames reached the first sensor ( $10 \mathrm{~m}$ from the point of ignition) was considered as the initial time of the explosion. Namely, the time of ignition of the gas explosion was 1,173 ms. Thus, the process from ignition to initiate the explosion to the moment when the maximum explosion pressure occurred at a location $20 \mathrm{~m}$ from the point of ignition took $196 \mathrm{~ms}$. At a location $20 \mathrm{~m}$ from the point of ignition, the durations of positive and negative explosion pressures were about $600 \mathrm{~ms}$ and $1,125 \mathrm{~ms}$, respectively. If someone stood at the location of $20 \mathrm{~m}$ from the explosive source in an underground coal mine, he or she would be successively impacted by positive explosion pressure for $600 \mathrm{~ms}$, and then negative explosion pressure for $1,125 \mathrm{~ms}$ after the gas explosion took place.

Figures 8-10 separately demonstrate the changes in explosion pressures with time at 40,80 , and $120 \mathrm{~m}$ from the point of ignition. As shown in Figure 8, the maximum explosion pressure at a location $40 \mathrm{~m}$ from the point of ignition was $0.136 \mathrm{MPa}$, which was lower than that $(0.156 \mathrm{MPa})$ at $20 \mathrm{~m}$ from the point of ignition. The durations of positive and negative explosion pressures also correspondingly decreased to $375 \mathrm{~ms}$ and $500 \mathrm{~ms}$, respectively: this corresponded exactly to the analysis of the explosion flame. At $40 \mathrm{~m}$ from the point of ignition, gas was gradually consumed, and therefore, the duration of explosion flames was correspondingly reduced. The explosion pressure also correspondingly decreased because of the interactive effect between the explosion flames and

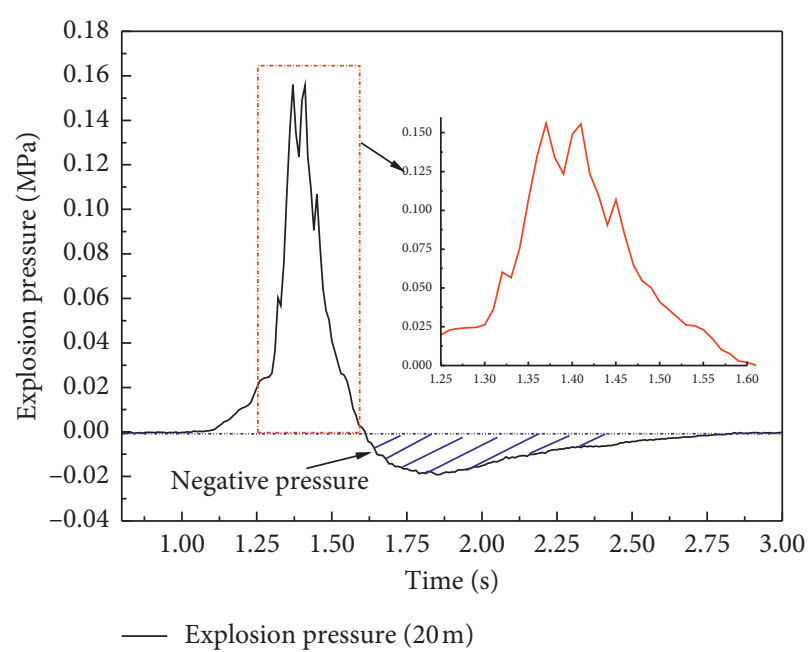

FIgURE 7: The explosion pressure-time curve at $20 \mathrm{~m}$ from the point of ignition.

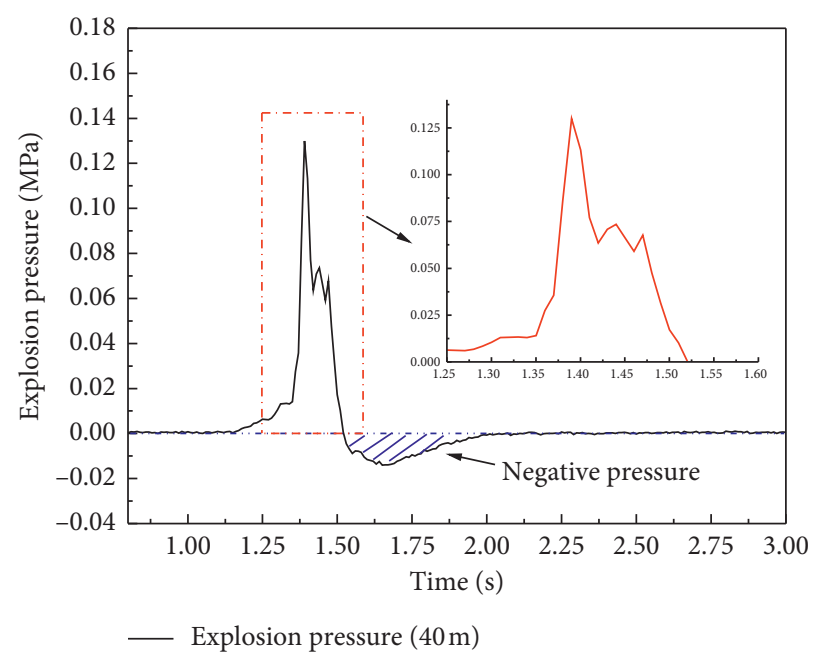

FIgURE 8: The explosion pressure-time curve at $40 \mathrm{~m}$ from the point of ignition.

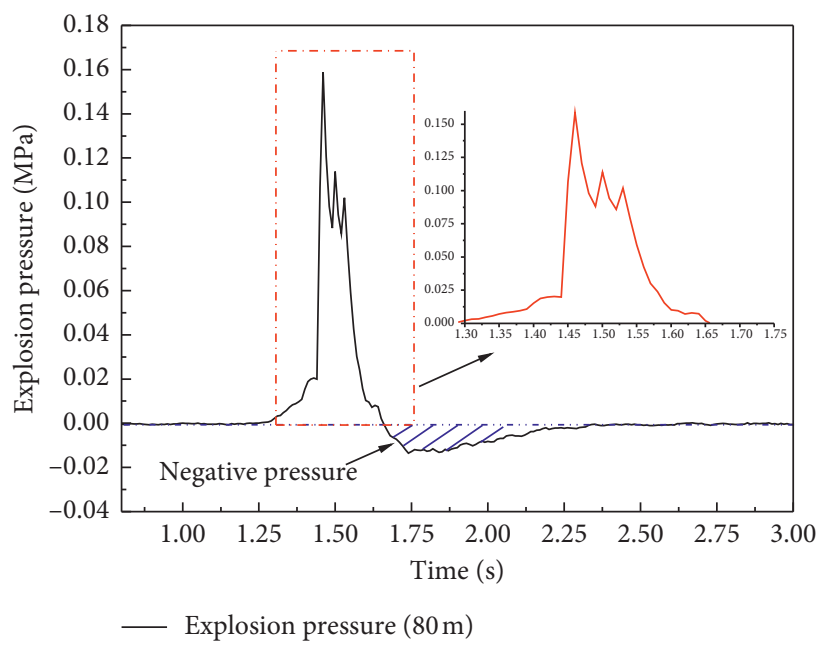

FIgURE 9: The explosion pressure-time curve at $80 \mathrm{~m}$ from the point of ignition position. 


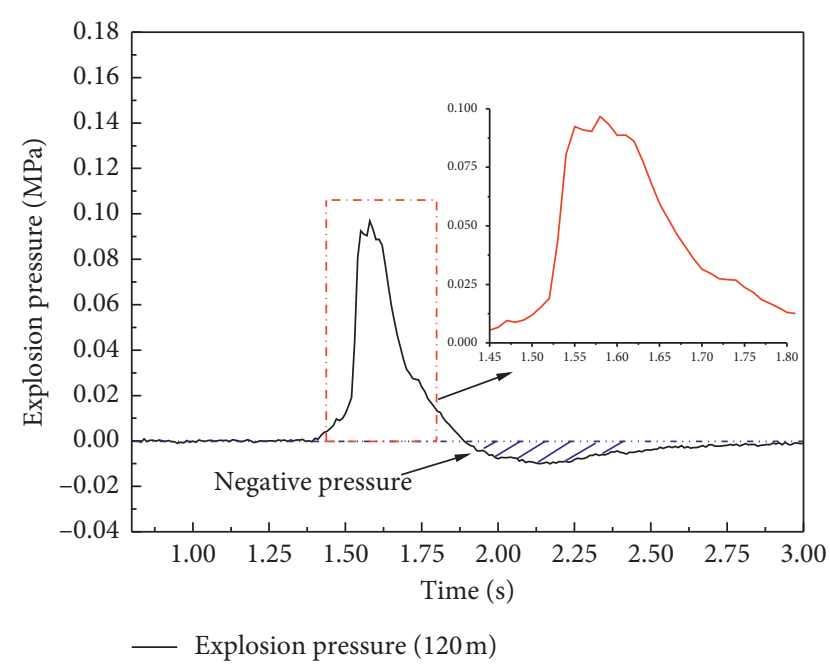

Figure 10: The explosion pressure-time curve at $120 \mathrm{~m}$ from the point of ignition.

pressures. In Figure 9, the explosion pressure at $80 \mathrm{~m}$ from the point of ignition increased to $0.161 \mathrm{MPa}$, which was the highest pressure recorded between 10 and $140 \mathrm{~m}$ from the point of ignition. By $120 \mathrm{~m}$, the maximum explosion pressure had fallen to $0.098 \mathrm{MPa}$, and correspondingly, the absolute value of negative pressure also gradually decreased.

\section{Harm to Animals}

4.1. Statistical Analysis of Casualties among SD Rats. After completing the explosion experiment, the casualties among SD rats in each cage were assessed after ventilating the laneway for $20 \mathrm{~min}$. The statistical results are displayed in Table 2. By comparing the explosion pressures at different locations, it can be speculated that there were more dead SD rats at the location with a higher explosion pressure. The explosion pressure $(0.161 \mathrm{MPa})$ was the largest at $80 \mathrm{~m}$ from the point of ignition, at which there were 13 dead SD rats with five SD rats surviving. At 200 and $240 \mathrm{~m}$, the explosion pressures were much smaller: only two or three SD rats were found dead. This also shows that the shock wave overpressure generated during the explosion was one of the main reasons for harm to the animals.

The survival rates of SD rats within $8 \mathrm{~h}$ after the explosion were calculated, as shown in Table 3: within $8 \mathrm{~h}$ after the gas explosion, the survival rates of SD rats in the No. 3, No. 5, and No. 6 cages did not decrease, while the survival rates of SD rats in the No. 1, No. 2, and No. 4 cages decreased to different extents. Some SD rats did not die instantly during the gas explosion but died after the explosion (mainly because the explosion blast caused visceral rupture among SD rats and burning damaged their respiratory system). It can be speculated that the No. 1, No. 2, and No. 4 cages were damaged by the explosion, such that SD rats were thrown out of the cages, and therefore, they were also injured. Some SD rats were drowned after falling in an area containing water between tracks in the laneway.
4.2. Analysis of Gas Explosion-Induced Harm to Animals. Figure 11 illustrates a comparison of SD rats before and after the gas explosion. It can be seen from the figure that, before the gas explosion, SD rats were all alive and had white coats. After the explosion, SD rats were injured to different extents. A majority of living SD rats exhibited the following symptoms: dyspnea, body tremble, fracture, and visceral rupture and bleeding. The SD rats in the No. 1 cage were burned all over, besides having the aforementioned symptoms.

The harm to animals is mainly demonstrated: hightemperature burn by explosion flames, overpressure damage caused by explosive blast waves, and toxicosis induced by incomplete combustion of gas.

High-temperature gas and flames were generated during the gas explosion. By analyzing the propagation, after the gasair mixture exploded, flames spread to a location some $40 \mathrm{~m}$ from the point of ignition, and therefore, the SD rats in the No. 1 cage installed at that location were injured by the flames. After observing casualties among animals after a gas explosion, it was found only SD rats in the No. 1 cage were burned, while those in cages 2 to 6 were not burned. By carrying out the test, it was inferred that although the duration of the explosion flames was only $634 \mathrm{~ms}$ at $40 \mathrm{~m}$ from the point of ignition, the hair on the majority of these SD rats was still burnt owing to the high-temperature conditions generated. In underground coal mines, if the gas was accumulated over a large area and thus there was a large amount of gas, the duration for which personnel in the vicinity of the explosive source were burned by the explosion and its ensuing flames was longer. Within the whole range of propagation of the gas explosion, the explosion pressure near the explosive source was not the highest, while personnel at that location were subjected to injury from both the explosive blast and flame burns, resulting in a greater number of casualties.

The explosive blast waves were imposed on animal bodies, causing damage to multiple organs therein. Additionally, under the dynamic pressure induced by high-speed flows, the SD rats fell, causing further injury (even fracturing limbs). Therefore, blast damage caused by the explosion was the primary reason behind the instant deaths of these animals. The experimental research showed that the ability of SD rats to bear dynamic pressure was weak. Fan [20] pointed out that when the pressure induced by the gas explosion was $20 \%$ higher than normal atmospheric pressure, SD rats died instantly: the higher the explosion pressure, the more serious the injuries, and the higher the mortality. The analysis of the propagation of explosive pressures indicated that the pressure induced by the gas explosion passed through multiple zones (including a pressure-relief zone after breaking the sealing film in the initial stage, a zone with strengthened explosion pressures, and a zone with attenuated explosion pressures) during its propagation along the laneway. Different explosion pressures that were generated in different zones resulted in different injury degrees. The analysis of accident cases showed that, in gas explosion accidents in coal mines, the death rates are different due to the different regions in which personnel are located. The difference in explosion pressure in different regions is one of the main reasons for the different death rates. 
TABLE 2: Casualty statistics: SD rat populations.

\begin{tabular}{lcccccc}
\hline Cage & $\# 1$ & $\# 2$ & $\# 3$ & $\# 4$ & $\# 5$ & $\# 6$ \\
\hline $\begin{array}{l}\text { Distance to the point of ignition } \\
(\mathrm{m})\end{array}$ & 40 & 80 & 120 & 160 & 200 & 240 \\
\hline
\end{tabular}

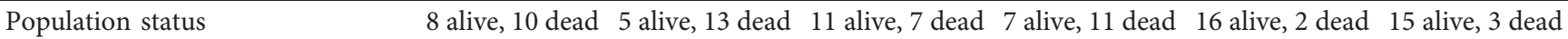

TABLE 3: Survival rates of SD rats within $8 \mathrm{~h}$ after the explosion.

\begin{tabular}{lcccccc}
\hline \multirow{2}{*}{ Time (h) } & \multicolumn{4}{c}{ Survival rate (\%) } \\
& No. 1 cage & No. 2 cage & No. 3 cage & No. 4 cage & No. 5 cage & No. 6 cage \\
\hline 0 & 44.4 & 27.8 & 61.1 & 38.9 & 88.9 & 83.3 \\
1 & 44.4 & 16.7 & 61.1 & 33.3 & 83.9 & 83.3 \\
4 & 44.4 & 16.7 & 61.1 & 33.3 & 83.3 \\
8 & 38.9 & 11.1 & 61.1 & 33.3 & 83.9 \\
\hline
\end{tabular}
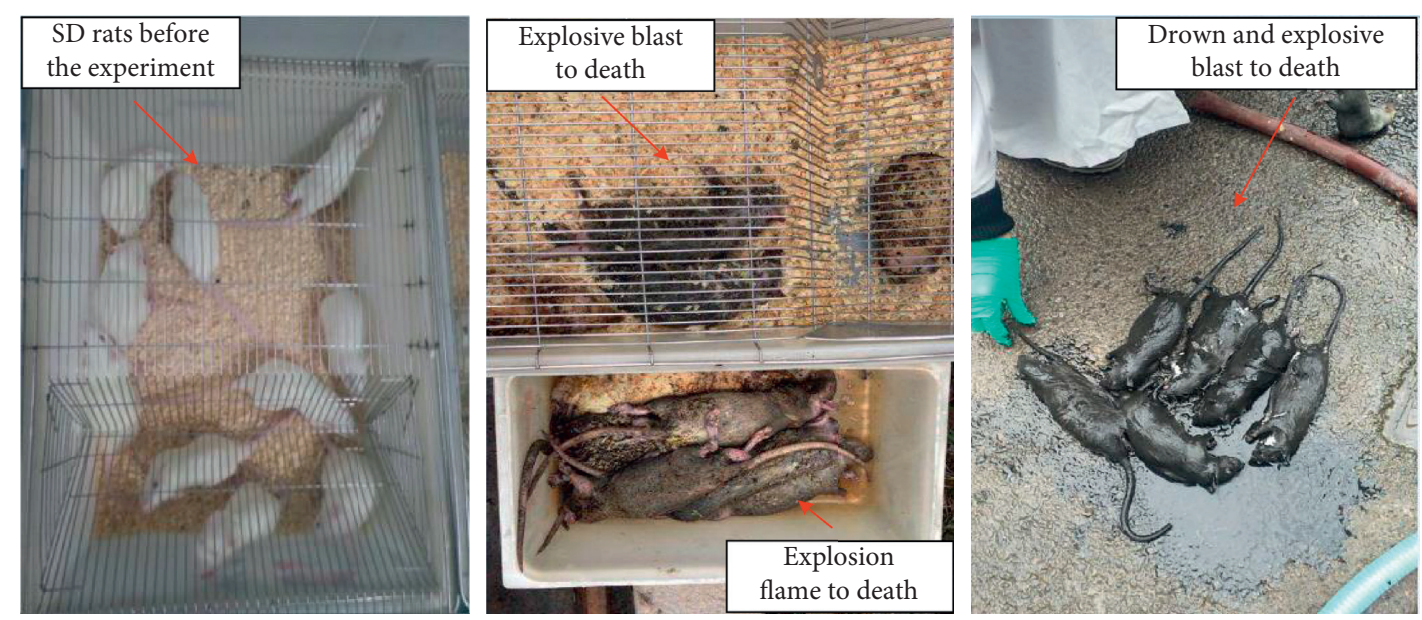

Figure 11: Comparison of SD rats before and after the gas explosion.

A significant amount of gas was involved in an explosion, while the incomplete reaction of the gas also occurred due to the lack of oxygen, thus generating a large amount of CO. Therefore, poisoning and asphyxiation are also important causes of death caused by gas explosions. Compared with the explosion flames, hazardous gas could result in larger-scale damage owing to it being diffused over a wider area. The gas concentration measured in the test was $9.0 \%$. In this context, gas was reacted completely in the explosion and the test laneway was ventilated after the explosion. Therefore, toxic damage to SD rats occurred at a low rate.

\section{Conclusion}

The harm to animals caused by a gas explosion was investigated experimentally by using a large laneway test system. During the explosion of $100 \mathrm{~m}^{3}$ of gas at a concentration (in the air) of $9.0 \%$ in the test laneway, the maximum explosion pressure reached $0.161 \mathrm{MPa}$. The explosive blast injury induced by this gas explosion was the major reason for the deaths of SD rats far from the point of ignition (i.e., at a distance of $240 \mathrm{~m}$ ). During the gas explosion, the explosive pressure could be described as occupying three zones (including a pressure-relief zone after breaking the film in the initial stage, a zone with strengthened explosion pressure and a zone with attenuated explosion pressure therein). Different explosion pressures were generated in different zones, leading to different amounts and severities of damage. The durations of positive and negative explosion pressures could reach 600 and 1,125 ms, respectively, and the positive and negative pressures generated due to the explosion caused severe blast damage. The explosion flames could spread to a location $40 \mathrm{~m}$ from the point of ignition, and their duration could reach $893 \mathrm{~ms}$. The SD rats in the cage located some $40 \mathrm{~m}$ from the point of ignition were also burned at high temperature as well as being damaged by the blast. Under the aforementioned experimental conditions, toxic damage to SD rats was low since the methane was fully reacted and the laneway was ventilated after the gas explosion.

\section{Data Availability}

The data that support the findings of this study are available from the corresponding author upon reasonable request.

\section{Conflicts of Interest}

The authors declare that there are no conflicts of interest. 


\section{Acknowledgments}

This work was supported by the National Key R\&D Program of China (Grant no. 2018YFC0807900) and the National Natural Science Foundation of China (Grant no. 51504285).

\section{References}

[1] G. Ke, L. Zimeng, J. Jinzhang et al., "Study on flame spread characteristics of flame-retardant cables in mine," Advances in Polymer Technology, vol. 2020, Article ID 8765679, 7 pages, 2020.

[2] K. Gao, S. Li, Y. Liu, J. Jia, and X. Wang, "Effect of flexible obstacles on gas explosion characteristic in underground coal mine," Process Safety and Environmental Protection, vol. 149, pp. 362-369, 2021.

[3] K. Gao, Z. Qi, J. Jia et al., "Investigation of coupled control of gas accumulation and spontaneous combustion in the goaf of coal mine," AIP Advances, vol. 10, no. 4, 2020.

[4] B. Nie, L. Yang, B. Ge, J. Wang, and X. Li, "Chemical kinetic characteristics of methane/air mixture explosion and its affecting factors," Journal of Loss Prevention in the Process Industries, vol. 49, pp. 675-682, 2017.

[5] M. J. Ajrash, J. Zanganeh, and B. Moghtaderi, "Methane-coal dust hybrid fuel explosion properties in a large scale cylindrical explosion chamber," Journal of Loss Prevention in the Process Industries, vol. 40, pp. 317-328, 2016.

[6] C. Wang, Y. Zhao, and E. K. Addai, "Investigation on propagation mechanism of large scale mine gas explosions," Journal of Loss Prevention in the Process Industries, vol. 49, pp. 342-347, 2017.

[7] Q. Zhang and Q. J. Ma, "Dynamic pressure induced by a methane-air explosion in a coal mine," Process Safety and Environmental Protection, vol. 93, 2015.

[8] I. G. Bowen, E. R. Fletcher, and D. R. Richmond, Estimate of Mans Tolerance to the Direct Effects of Air Blast, Lovelace Foundation for Medical Education and Research, Albuquerque, NM, USA, 1968.

[9] M. A. Mayorga, "The pathology of primary blast overpressure injury," Toxicology, vol. 121, no. 1, pp. 17-28, 1997.

[10] A. Knauf, "Blast injury causing extensive brain injury and elevated skull fracture," Indian Journal of Neurotrauma, vol. 11, no. 01, pp. 64-67, 2014.

[11] V. Rubovitch, M. Ten-Bosch, O. Zohar et al., "A mouse model of blast-induced mild traumatic brain injury," Experimental Neurology, vol. 232, no. 2, pp. 280-289, 2011.

[12] A. Saljo, M. Mayorga, H. Bolouri, B. Svensson, and A. Hamberger, "Mechanisms and pathophysiology of the lowlevel blast brain injury in animal models," Neuroimage, vol. 54, 2011.

[13] H. Z. Toklu, Z. Yang, S. Oktay et al., "Overpressure blast injury-induced oxidative stress and neuroinflammation response in rat frontal cortex and cerebellum," Behavioural Brain Research, vol. 340, 2017.

[14] A. J. Januszkiewicz, T. G. Mundie, and K. T. Dodd, "Maximal exercise performance-impairing effects of simulated blast overpressure in sheep," Toxicology, vol. 121, no. 1, pp. 51-63, 1997.

[15] J. Hines-Beard, J. Marchetta, S. Gordon, E. Chaum, E. E. Geisert, and T. S. Rex, "A mouse model of ocular blast injury that induces closed globe anterior and posterior pole damage," Experimental Eye Research, vol. 99, pp. 63-70, 2012.
[16] J. M. Petras, R. A. Bauman, and N. M. Elsayed, "Visual system degeneration induced by blast overpressure," Toxicology, vol. 121, no. 1, pp. 41-49, 1997.

[17] I. Cernak, A. C. Merkle, V. E. Koliatsos et al., "The pathobiology of blast injuries and blast-induced neurotrauma as identified using a new experimental model of injury in mice," Neurobiology of Disease, vol. 41, no. 2, pp. 538-551, 2011.

[18] R. A. Bauman, N. Elsayed, J. M. Petras, and J. Widholm, "Exposure to sublethal blast overpressure reduces the food intake and exercise performance of rats," Toxicology, vol. 121, no. 1, pp. 65-79, 1997.

[19] K. Gao, "Study on the propagation law of gas explosion in the space based on the goaf characteristic of coal mine," Safety Science, vol. 127, 2020.

[20] X. T. Fan, Z. Li, and C. Zhouquan, "Experimental study on harm of gas explosion to animals," Mining Safety \& Environmental Protection, vol. 4, pp. 7-8+83, 2005. 